University of Nebraska - Lincoln

DigitalCommons@University of Nebraska - Lincoln

US Department of Energy Publications

U.S. Department of Energy

2004

\title{
Microscale Distribution of Cesium Sorbed to Biotite and \\ Muscovite
}

James Mckinley

Pacific Northwest National Laboratory, james.mckinley@pnl.gov

John M. Zachara

Pacific Northwest National Laboratory, john.zachara@pnl.gov

Steven Heald

Pacific Northwest National Laboratory

Alice Dohnalkova

Pacific Northwest National Laboratory

Matthew Newville

Argonne National Laboratory

See next page for additional authors

Follow this and additional works at: https://digitalcommons.unl.edu/usdoepub

Part of the Bioresource and Agricultural Engineering Commons

Mckinley, James; Zachara, John M.; Heald, Steven; Dohnalkova, Alice; Newville, Matthew; and Sutton, Steve, "Microscale Distribution of Cesium Sorbed to Biotite and Muscovite" (2004). US Department of Energy Publications. 225.

https://digitalcommons.unl.edu/usdoepub/225

This Article is brought to you for free and open access by the U.S. Department of Energy at DigitalCommons@University of Nebraska - Lincoln. It has been accepted for inclusion in US Department of Energy Publications by an authorized administrator of DigitalCommons@University of Nebraska - Lincoln. 


\section{Authors}

James Mckinley, John M. Zachara, Steven Heald, Alice Dohnalkova, Matthew Newville, and Steve Sutton 


\section{Microscale Distribution of Cesium Sorbed to Biotite and Muscovite}

\author{
JAMES P. MCKINLEY,*,† \\ JOHN M. ZACHARA, ${ }^{\dagger}$ \\ STEVEN M. HEALD, †, \\ ALICE DOHNALKOVA, \\ MATTHEW G. NEWVILLE, § AND \\ STEVE R. SUTTON \\ Pacific Northwest National Laboratory, \\ Richland, Washington 99352, PNC-CAT and GSE-CARS, \\ Argonne National Laboratory, Argonne, Illinois 60439
}

Individual 1-3 $\mathrm{mm}$ biotite and muscovite clasts from Hanford sediment were contacted with $0.08 \mathrm{M} \mathrm{CsNO}_{3}$. They were examined using electron or X-ray microprobe methods, as intact specimens or sectioned perpendicular to their basal planes. $\mathrm{Cs}^{+}$was observed to preferentially sorb to mica edges, steps on mica surfaces, or fractured regions. The localization of Cs conformed to hypothesized strong binding to frayed edge sites in preference to sites on basal planes. In section, $\mathrm{Cs}^{+}$was found to penetrate the mica interior, forming discrete zones of concentration, particularly in muscovite. In biotite, Cs was more abundant, permeating the clasts, but also forming discrete zones of higher concentration. Concentrated Cs on both clast edges and within clast interiors corresponded to mic roscopic but relatively extensive zones where $\mathrm{K}$ was depleted. The localization of sorbed $\mathrm{Cs}$ in areas where $\mathrm{K}$ was depleted suggested that weathering reactions had caused the formation of frayed edge sites within the micas. $\mathrm{Cs}^{+}$accessed crystal interiors by diffusion along channels following crystal defects, cracks, or partings where pore fluids had previously migrated to form the interior alteration zones. On the nanometer scale, areas with localized Cs were disrupted, confirming that frayed edge sites were developed in clast interiors.

\section{Introduction}

Cesium-137 ( $\left.\mathrm{t}_{1 / 2}=30.17 \mathrm{y}\right)$ is an important soil and vadose zone contaminant at the Hanford Site in southeastern Washington, which was active as a plutonium synthesis facility during the Manhattan Project and the Cold War. The chemical processing of fuel rods generated huge volumes of radioactive waste, some of which leaked from underground storage tanks or was disposed directly to the ground. About $4 \times 10^{16} \mathrm{~Bq}$ ( 1 million $\mathrm{Ci}$ ) of ${ }^{137} \mathrm{Cs}$ was leaked into the vadose zone, and sediment samples have been recorded to contain as much as $10^{9} \mathrm{~Bq} \mathrm{~g}^{-1}\left(10^{10} \mathrm{pCi} \mathrm{g}^{-1}\right)^{137} \mathrm{Cs}$. The site's micaceous sediment shows a high affinity for $\mathrm{Cs}^{+}$, but cases of expedited $\mathrm{Cs}^{+}$migration have been observed when high-level waste was the carrier. ${ }^{1}$ The residence and retention of ${ }^{137} \mathrm{Cs}$ in

* Corresponding author address: Pacific Northwest National Laboratory, MSIN K8-96, P.O. Box 999, Richland, WA 99352; phone: (509) 376-6573; fax: (509) 376-3650; e-mail: james.mckinley@pnl.gov.

+ Pacific Northwest National Laboratory.

₹ PNC-CAT, Argonne National Laboratory.

$\S$ GSE-CARS, Argonne National Laboratory.
Hanford's unconsolidated sediments thus has significant consequences for deciding how and whether to remediate them.

Micaceous mineral s present a favorable environment for $\mathrm{Cs}^{+}$adsorption. ${ }^{2-6}$ They are common phyllosilicateminerals with a crystallographic sheet structure that consists of metal ions, principally aluminum and silicon, bound in octahedral and tetrahedral coordination, respectively, with oxygen. ${ }^{7}$ Each sheet includes a central octahedral layer between two tetrahedral layers (Figure 1). Cations of lesser charge may substituteisomorphically for aluminum and silicon, imposing a net negative structural charge. Sheets are bound together by charge-compensating interlaminar $\mathrm{K}^{+}$, which is weakly hydrated and fits into the mated ditrigonal cavities on the surfaces of adjacent sheets. The monovalent cations $\mathrm{Cs}^{+}$and $\mathrm{Rb}^{+}$are also weakly hydrated and similar in size to $\mathrm{K}^{+}$, and so are strongly retained when substituted for $\mathrm{K}^{+}$.

The importance of micaceous minerals for sorbing and retaining $\mathrm{Cs}$ has long been recognized. In addition to interrelated studies conducted by our group, ${ }^{8-12}$ the retention of $\mathrm{Cs}^{+}$by micas has been intensively studied by others. ${ }^{2-6,13-20}$ Much of this work, using contaminated sediments, mineral separates, or representative specimen minerals, was doneto understand the behavior of anthropogenic Cs at sites that were contaminated in ways similar to the sediment at Hanford. Theoverall set of observations from the earlier work formed a relatively uniform framework for understanding and modeling $\mathrm{Cs}^{+}$interaction with micaceous minerals. In summary, the observations were (i) sorption occurred at two rates, a rapid initial sorption step followed by continued slow sorption during prolonged contact with the sorbing phase, (ii) desorption also proceeded at two rates, with rapidly and slowly desorbing fractions, (iii) when the adsorption event was prolonged, the slowly desorbing $\mathrm{Cs}^{+}$pool was a larger fraction of the whole, and (iv) in sediments where $\mathrm{Cs}^{+}$had a long residence, a significant fraction of adsorbed $\mathrm{Cs}^{+}$was resistant to desorption involving exposure to competing cations of varying relative selectivity and concentration.

The binding sites thought to explain these observations ${ }^{5}$ (Figure 1) include(i) exchangesites on phyllosilicatesurfaces, i.e., the accessible edge and basal plane sites, (ii) selective frayed edge site (FES) formed by the removal of $\mathrm{K}^{+}$from micainterlayers during natural weathering, and (iii) interlayer sites populated by the diffusion and displacement of $\mathrm{K}^{+}$by $\mathrm{Cs}^{+}$from FES. The wedge-shaped FES occupy the transition from an interlayer spacing of $1.4 \mathrm{~nm}$ at the weathered edge (where $\mathrm{K}^{+}$ions have been removed), to a spacing of $1.0 \mathrm{~nm}$ in internal unweathered interlayer space. Since they occupy a small fractional area on the mica surface, the abundance of FES is relatively small. The FES transition zone provides a favorable environment for binding weakly hydrated cations, such as $\mathrm{K}^{+}, \mathrm{Cs}^{+}$, and $\mathrm{NH}_{4}{ }^{+}$, which may readily displace weakly held, more strongly hydrated cations such as $\mathrm{Na}^{+}$. Two-step adsorption could thus be explained by the rapid occupation of abundant low-affinity sites, followed by a fractional increase of occupancy in sparse high-affinity FES. The desorption-resistant $\mathrm{Cs}^{+}$could occupy interlayer sites or could represent $\mathrm{Cs}^{+}$trapped by interlayer collapse.

Recent studies focusing on ${ }^{137} \mathrm{C}$ sat Hanford supplemented and improved the understanding of $\mathrm{Cs}^{+}$migration and retardation in micaceous sediments. In these sediments, ${ }^{137} \mathrm{Cs}$ was controlled by sorption to biotite and muscovite, with no other significant sorbing phases identified after exhaustive characterization of waste-impacted sedimentsusing scanning electron microscopy and autoradiography. ${ }^{12}$ Experimental investigations showed that the interaction of $\mathrm{Cs}^{+}$with these 


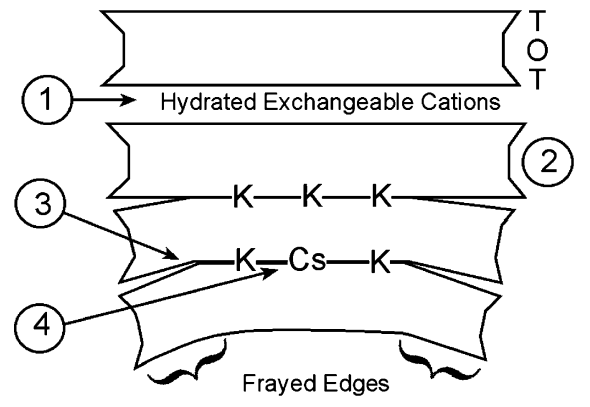

FIGURE 1. Schematic diagram of the mica structure: TOT, tetrahedral-octahedral-tetrahedral sheet structure; $K$ and $C s$, interlayer cations; edges are "frayed" by the removal of interlayer $\mathrm{K}^{+}$. Potential sites for $\mathrm{Cs}^{+}$sorption: (1) cation exchange sites on the basal plane, (2) edge sites, (3) frayed edge sites, (4) replacement of $\mathrm{K}^{+}$by $\mathrm{Cs}^{+}$in interlayer sites.

sediments could be described using a four-parameter model with high- and low-affinity sites, including the effects of weakly interacting smectites; ${ }^{10,11}$ the low-affinity component became more significant at relatively high fractional surface loadings. Desorption from contaminated sediments was controlled by a complexinteraction of processes and included rapidly reversible and nonreversible components. ${ }^{8}$ The desorption ratewas dependent on electrolyteconcentration, electolyte cation, and temperature. ${ }^{21}$ The contaminated sediments were observed to have been significantly altered by interaction with highly alkaline wastes, with only $40 \%$ of the total $\mathrm{Cs}^{+}$measured to be exchangeable. In laboratory studies using contaminated sediments, the extent and rate of $\mathrm{Cs}^{+}$desorption were modeled to be influenced by surface armoring, intraparticle diffusion, and the collapse of edgeinterlayer sites in the presence of $\mathrm{K}^{+}, \mathrm{Cs}^{+}$, or $\mathrm{Rb}^{+}$. In applying laboratory measurements of $\mathrm{Cs}^{+}$sorption to the field, however, using sorption constants obtained from composited uncontaminated sediments, the two-site model successfully simulated the subsurface distribution of $\mathrm{Cs}^{+}$at Hanford. ${ }^{10,21}$

Theconceptual model represented by earlier experimental observations was thus used to construct numerical models that could simulate the laboratory and field behavior of $\mathrm{Cs}^{+}$. In large part, these simulations relied on an understanding of the mineralogy of the micaceous minerals, includingtheir chemical weathering mechanisms. However, there was no effort to confirm the distribution of sorbed $\mathrm{Cs}^{+}$on and within mica clasts by observation. In addition, there were some inconsistencies between theoretical and conceptual considerations of $\mathrm{Cs}^{+}$binding that could possibly be clarified by observations of $\mathrm{Cs}^{+}$on mica surfaces. For example, very slow desorption from some micaceous sediments ${ }^{3,13,22}$ could be due to distribution of $\mathrm{Cs}^{+}$in areas that were relatively inaccessible to desorbing cations. We thought that demonstrating theassociation of $\mathrm{Cs}^{+}$with specific chemical regimes on the mica surface could bring some new and relevant information for understanding its behavior in the environment. In this investigation, we applied electron microprobe (EMP), scanning electron microscopy (SEM), transmission electron microscopy (TEM), and X-ray microprobe (XMP) methods to examine the spatial distribution of $\mathrm{Cs}^{+}, \mathrm{K}^{+}$, and other ions in micas that had been contacted with $\mathrm{CsNO}_{3}$ solutions in the laboratory.

\section{Methods}

Micas were hand-picked from Hanford formation sediments retrieved from a vadosezone borehole proximate to theS-SX Tank Farm at the Hanford Site in south central Washington state. The Hanford formation is comprised of Pleistocene catastrophic flood deposits from glacial Lake M issoula. The phyllosilicateand associated mineralogy have been described el sewhere. ${ }^{11}$ The micas were segregated into dark biotiteand colorless muscovite species on the basis of appearance (a small fraction of mica clasts were sheathed in vermiculitic alteration and were not studied). The mica clasts described herewere placed in contact with $20 \mathrm{~mL}$ of an aqueous solution of $\mathrm{CsNO}_{3}(0.08 \mathrm{M})$, in small batches of ca. 12 clasts of $1-3$ mm diameter, for 14 or 28 days at room temperature, washed with deionized water, and air-dried. Mica surfaces were examined directly. The internal portions of individual clasts were examined by imbedding them in epoxy resin and making ca. $60 \mu \mathrm{m}$ thick sections perpendicular to the basal planes. (Henceforth, for clarity, $\mathrm{Cs}^{+}$is used in discussing the potentially mobile ion, and Cs is used in reference Cs more generally and to measurements on the solid phase.)

For EMP analysis, elemental abundances were imaged bytuning each of three wavelength-dispersivespectrometers (WDS) to the X-ray emission lines for Fe, K, and Cs using standard materials. The JEOL 8600 was run with a $20 \mathrm{keV}$ electron beam at a current of $20 \mathrm{nA}$ under digital positional control. The X-rays were collected for $0.2 \mathrm{~s}$ for each element from each point in a 512 by 512 grid on the sample surface at a resolution determined by the magnification, typically yielding a 200-600 nm pixel size. Scanning electron photomicrographs were made using a JEOL 6340F scanning electron microscope at $10 \mathrm{keV}$ and $10 \mathrm{nA}$ beam current.

For TEM analysis, sections were examined using a JEOL 2010 high-resolution transmission electron microscope equipped with a $\mathrm{LaB}_{6}$ filament operating at $200 \mathrm{kV}$. M aterial was embedded in acrylic resin, and blocks were sectioned to a $70 \mathrm{~nm}$ thickness on a microtome (Leica Ultracut UCT) to obtain cross sections of individual mica particles. Sections were mounted on 200mesh copper grids coated with Formvar support film sputtered with carbon. Electron energy loss spectroscopy (EELS) was used for the detection and mapping of compositional information.

For XMP analysis, measurements were made at the Argonne National Laboratory Advanced Photon Source on either thePacific Northwest Consortium CollaborativeAccess Team (PNC-CAT) beamline ${ }^{23}$ or the GeoSoilEnviro Consortium for Advanced Radiation Sources (GSE-CARS) beamline. The samples were mounted to an open stepper motor-driven stage on an optical bench and moved relative to the X-ray beam, which was focused by Kirkpatrick-Baez mirrors to a diameter of $6 \mu \mathrm{m}$ on the sample surface. Samples were tilted $30^{\circ}$ from normal incidence in the horizontal to facilitate observation, and element-characteristic X-rays weredetected with either a WDS or an energy-dispersive spectrometer (EDS). The X-ray flux was about $5 \times 10^{11}$ photons $\mathrm{s}^{-1}$. The beam energy was selected with a $\mathrm{Si}(111)$ double-crystal monochromator with an energy resolution of $\Delta E / E=1.4 \times$ $10^{-4}$. For imaging, the incident energy was set to $7110 \mathrm{eV}$ to only partially excitetheFesignal, avoiding detector saturation from high concentrations of $\mathrm{Fe}$. The limit of detection was approximately $5 \times 10^{9} \mathrm{Cs}$ atoms in the beam spot. Weight percent concentrations were not measured. Comparative results were obtained by observing the characteristic X-ray intensities for $\mathrm{K}$ and $\mathrm{Cs}$ across the area analyzed.

For each XMP image, intensities were mapped and assigned falsecolorsusing Noesys software (Fortner Research, Sterling, VA). Digital EMP, SEM, and XMP images were manipulated and merged using Photoshop (Adobe Systems).

\section{Results and Discussion}

Although the distribution of Cs on mica surfaces was variable within and between clasts, results for the 14- and 28-day exposures were the same within our ability to measurethem. Micas that had not been exposed to $\mathrm{CsNO}_{3}$ were analyzed by EMP and XMP methods and did not contain Cs detectable by either method (not shown). 

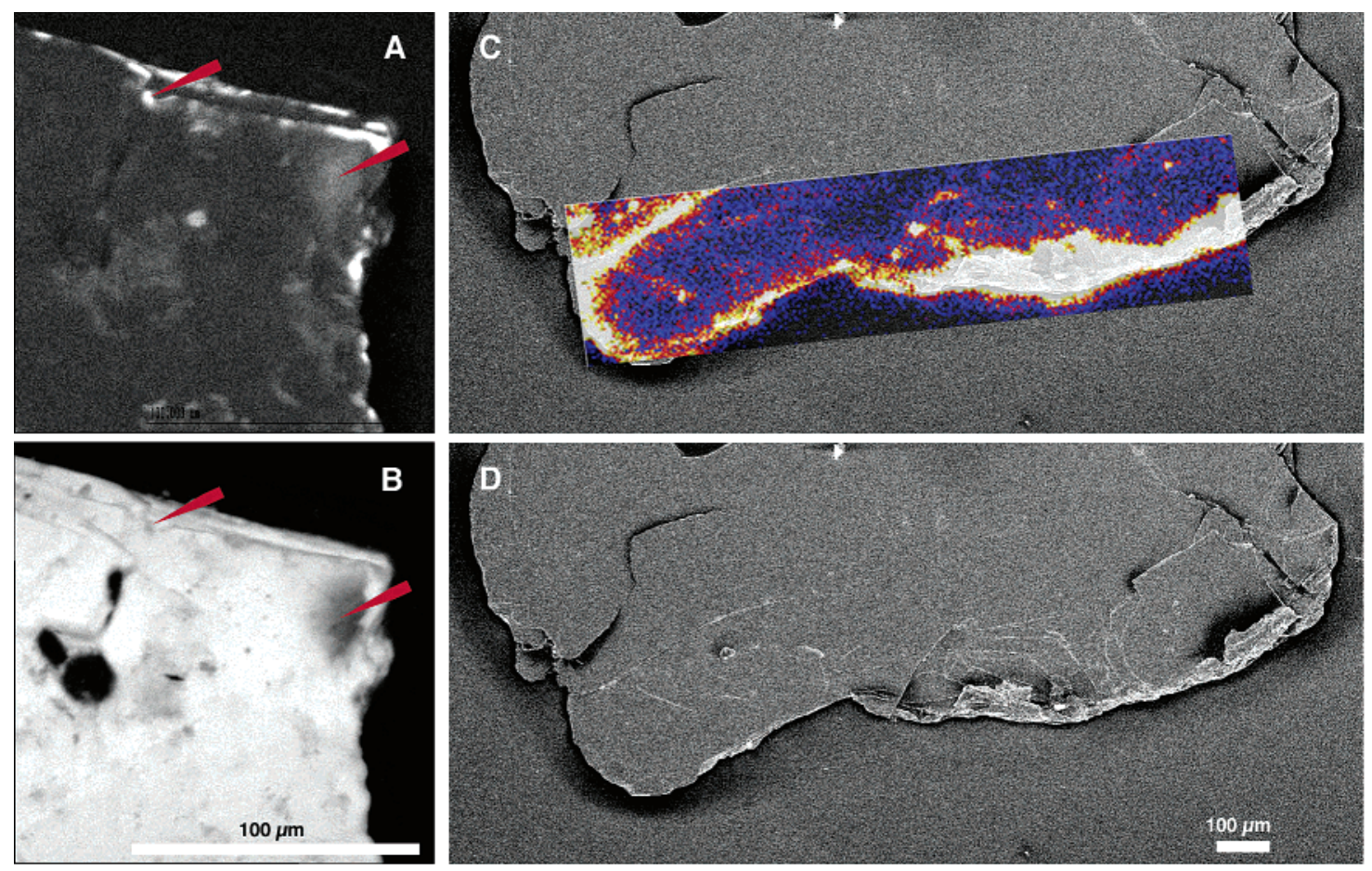

FIGURE 2. Cs on mica surfaces: left, Cs associated with biotite, elemental abundance map for Cs (A) and K (B); right, Cs associated with muscovite, superimposed secondary-electron SEM and false-color XMP image (C) and SEM image alone (D).

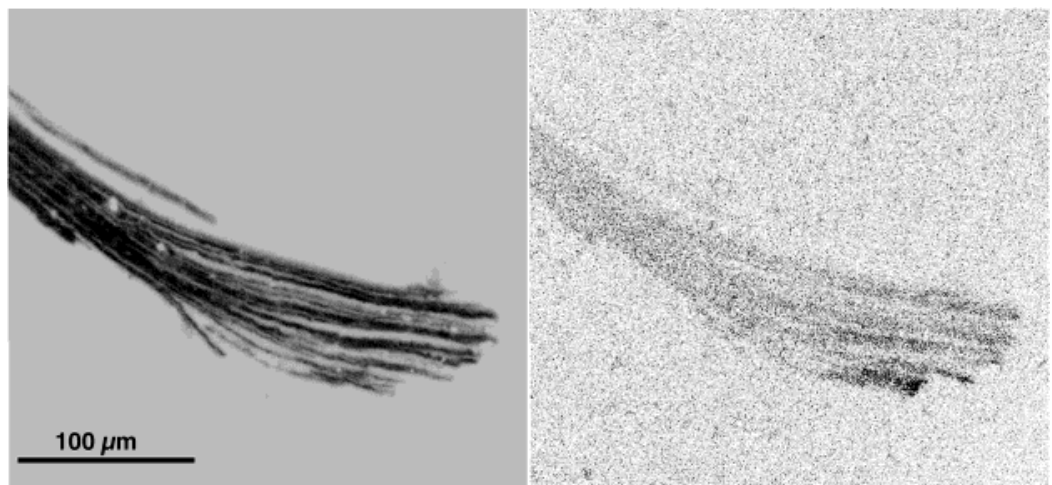

FIGURE 3. EMP elemental abundance maps for K (left) and Cs (right) on splayed muscovite. Darkness is proportional to concentration.

Clasts were imaged in terms of elemental abundances using XMP and EMP methods, and secondary electron or optical images were collected to provide a morphological reference for the compositional data. Since K was present in relatively high concentration (about $70-80 \mathrm{~g} \mathrm{~kg}^{-1}$ in muscovite and biotite$^{7}$ ), abundance maps for K served to image clast morphology and provide data for comparison with Cs abundance. The results for mica surfaces (Figure 2) showed that $\mathrm{Cs}^{+}$was preferentially sorbed where individual sheet boundaries were expressed as steps on the clast surfaces. These steps were most abundant at, and of course defined, clast boundaries, so the $\mathrm{cs}$ was most abundant on clast edges. Examination of the clast surface, particularly the surface of biotite, showed also that there were significant zones of $\mathrm{K}$ depletion and step edges not associated with clast boundaries (arrows, Figure 2A,B). It was apparent that $\mathrm{K}$ was depleted in areas with the most abundant Cs; this result was consistent with the formation of FES due to weathering reactions.

Muscovite sorbed less $\mathrm{Cs}^{+}$than biotite (using EMP analysis, Cs was readily detectible in biotite, but near the limit of detection in muscovite, e.g., Figures 2 and 3 ). Biotite is an Fe-rich trioctahedral mica (all sites in the octahedral sheet are occupied, and substitutions of divalent cations for $\mathrm{Al}^{3+}$ are common), whereas muscovite is dioctahedral (two- thirds of the octahedral sites are occupied by $\mathrm{Al}^{3+}$, and the rest are vacant). The net negative structural charge in muscovite arises predominantly from $\mathrm{Al}^{3+}$ substitution for $\mathrm{Si}^{4+}$ in the tetrahedral sites, so that the charge deficiency is just adjacent to the interlayer space, and dioctahedral micas bind $\mathrm{K}^{+}$morestrongly than trioctahedral micas. ${ }^{24}$ Muscovite thus retains $\mathrm{K}^{+}$much more strongly than biotite. It is also the most weathering-resistant mica. ${ }^{7,25}$ These mineralogical differences suggest that, under identical weathering conditions, muscovite could be expected to develop fewer Cscomplexing FES than biotite.

A sectioned muscovite (Figure 3 ) illustrated the cross sectional effects of chemical and physical weathering. The muscovite clast fanned as a result of exfoliation during weathering, with small domains of kaolinitization or primary mineral inclusions (light areas in the $\mathrm{K}$ image). In the EMP image, the depletion of $\mathrm{K}$ was not evident, and Cs was observed at low abundances, very near the limit of detection. The flayed lamina were observed at a size $(2-10 \mu \mathrm{m})$ that was far larger than the weathering transition between 1.0 and $1.4 \mathrm{~nm}$ spacings, but their evident larger-scalealteration was a manifestation of alteration at a much finer scale. And, although Cs was near the limit of detection, it was obviously 


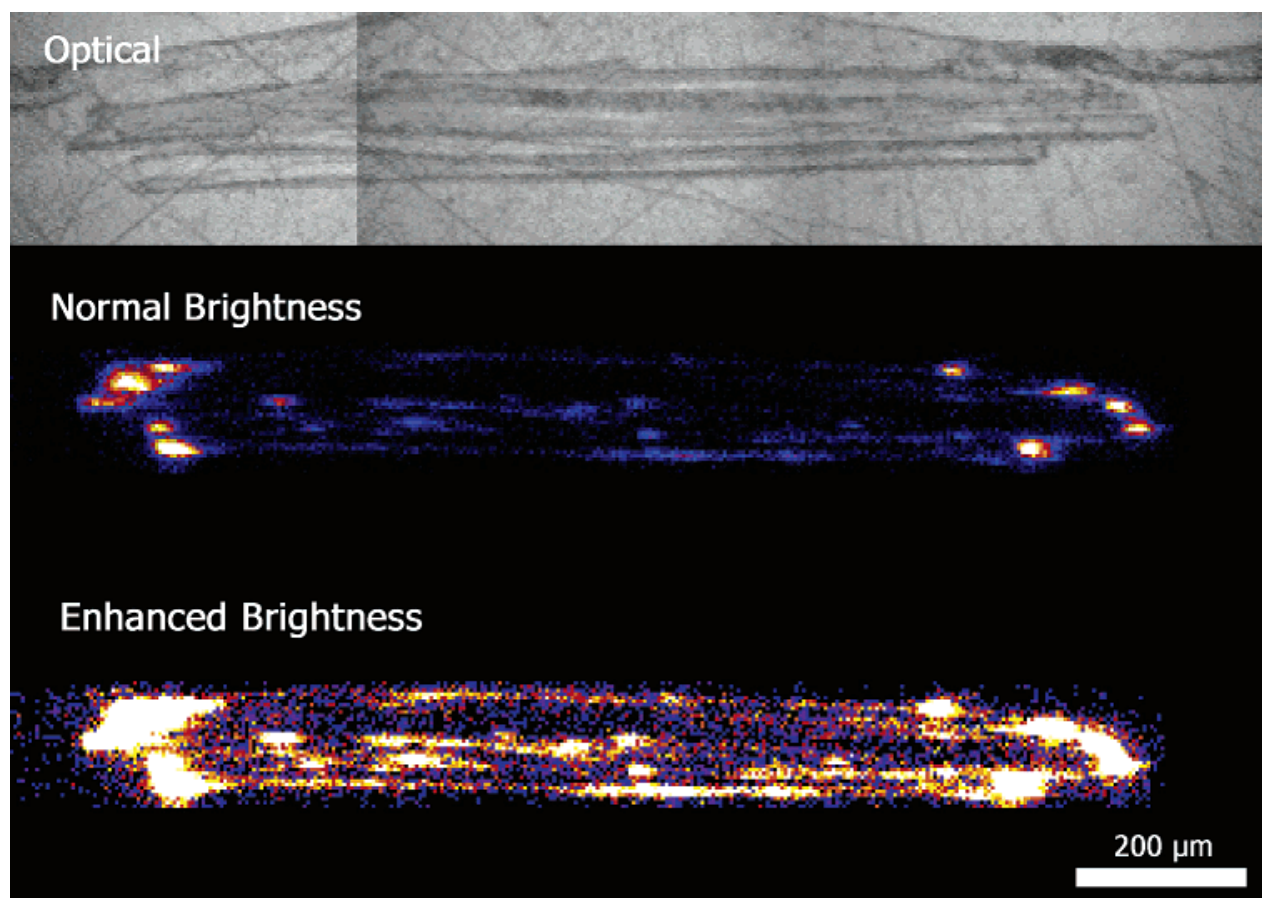

FIGURE 4. Optical image of sectioned muscovite clast with associated false-color Cs abundance. Cs is abundant at the clast ends (w here FES were expected), and at the clast interior (where FES developed due to chemical weathering).

more abundant in the distal, delaminated regions of the muscovite clast.

TheXMP provided more precise detail on the distribution of $\mathrm{Cs}$ in micas than the EMP. For muscovite (Figure 4) the data showed a striking heterogeneity in the distribution of Cs. Cs was concentrated near clast edges, as would be expected if the intensity of mechanical and chemical weathering, and the formation of FES, were greatest at the edges. Cs was not limited to edges, however, nor was it uniformly distributed, but was concentrated in discretezones 3-6 $\mu \mathrm{m}$ across at clast edges and in the particle interior. The clustered near-edge Cs may indicate differential weathering and the development of zones of relatively abundant FES; however, themovement of Cs into the interiors of mica books by meansother than diffusion along interlayer space has not been predicted or previously investigated. ${ }^{5}$ The image in Figure 4 was a two-dimensional slice of a three-dimensional mineral clast, and we were aware of the possibility that the results were a two-dimensional expression of a process occurring in three dimensions. However, the deep penetration of Cs into the mica grain interiors argued against the interlayer diffusional replacement of $\mathrm{K}^{+}$by $\mathrm{Cs}^{+}$: the distances traveled were too great.

Experimental studies of the potential rate of $\mathrm{Cs}^{+}$diffusion and replacement of $\mathrm{K}^{+}$in interlayer space indicate that it is extremely slow. ${ }^{4}$ In an analogous study, early work with $\mathrm{Rb}^{+}$ sorbed to micas also indicated limited migration of this $\mathrm{Cs}^{+}$like cation into interlaminar space. ${ }^{25}$ In that study, micas were harshly treated to extract $\mathrm{K}^{+}$and then saturated with $\mathrm{Mg}^{2+}$, after which $\mathrm{Rb}^{+}$was allowed to exchange with $\mathrm{Mg}^{+}$ and residual $\mathrm{K}^{+}$in the induced FES. Rb was found on the solid onlyin the vicinity of stepsand partings, and its relation to $\mathrm{Mg}^{+}$suggested that the $\mathrm{Rb}^{+}$induced the collapse of FES, causing its mobility to beself-limiting. This early observation was consistent with recent experimental evidence suggesting that excess $\mathrm{K}^{+}$could cause interlayer collapse and impede $\mathrm{Cs}^{+}$desorption. ${ }^{8} \mathrm{~A}$ more likely explanation for the results in Figure 4 was the migration of $\mathrm{Cs}^{+}$along microfractures, cleavage partings, and crystallographic dislocations within the mica clasts to intragrain areas where FES were relatively abundant. Studies of mica weathering suggested that mica interiors were accessible to weathering solutions and reactions. The formation of vermiculite during the weathering of biotite, for example, was observed to include the formation of etch pits parallel to mica sheets, enclosing secondary noncrystalline and poorly crystalline clays. ${ }^{26}$ These pits, occurring sporadically within mica clasts, were interpreted to be the result of dissolution at preexisting points of weakness, suggesting that the aqueous phase could access clast interiors. Weathering could thus have generated concentrated zones of FES in mica interiors, and the channels responsible for FES formation could act as conduits for $\mathrm{Cs}^{+}$ diffusion.

In previousstudies, ${ }^{2-5,13,14}$ FESwere typically and logically thought to be situated along the weathered edges of mica clasts. This approach was supported by correlations of sorption capacity and $\mathrm{Cs}^{+} \mathrm{Kd}$ to geometric surface area, ${ }^{16}$ suggesting that FES were located on edges. The finding of FES in grain interiors as well as at edges is significant for the immobilization of ${ }^{137} \mathrm{Cs}^{+}$, since it implies that the effective surface area is larger than apparent, and could also explain thefractional migration of sorbed $\mathrm{Cs}^{+}$from "weak" to "strong" sites over time.

The sorption of $\mathrm{Cs}^{+}$was qualitatively different between biotite and muscovite. Biotite was extensively weathered, with abundant partings, fractures, and zones of $\mathrm{K}$ depletion (Figure 5). (In Figure 5, the brightness is proportional to the concentration of $\mathrm{Fe}$ and $\mathrm{K}$, and to an increasing average atomic number for backscattered electron intensity, BSE.) Cs was generally detectable across the interiors of biotite clasts at relatively low abundance, with some areas having significantly higher concentrations (arrows in Figure 5). A comparison of morphology (BSE) with Kabundanceindicated areas of $\mathrm{K}$ depletion where the clast was physically intact. CS tended to be concentrated in those areas. The retention of $\mathrm{Cs}^{+}$was thus apparently facilitated by weathering and the leaching of $\mathrm{K}^{+}$to produce abundant FES. Careful inspection of the distribution of $\mathrm{Fe}$ indicates also that Fe was more abundant in areas where Cs was concentrated (arrows). Increased Fe abundance at areas of relatively abundant Cs may have been due to $\mathrm{Fe}(\mathrm{II})$ oxidation and the resultant crystallographic changes and formation of FES. The micas 


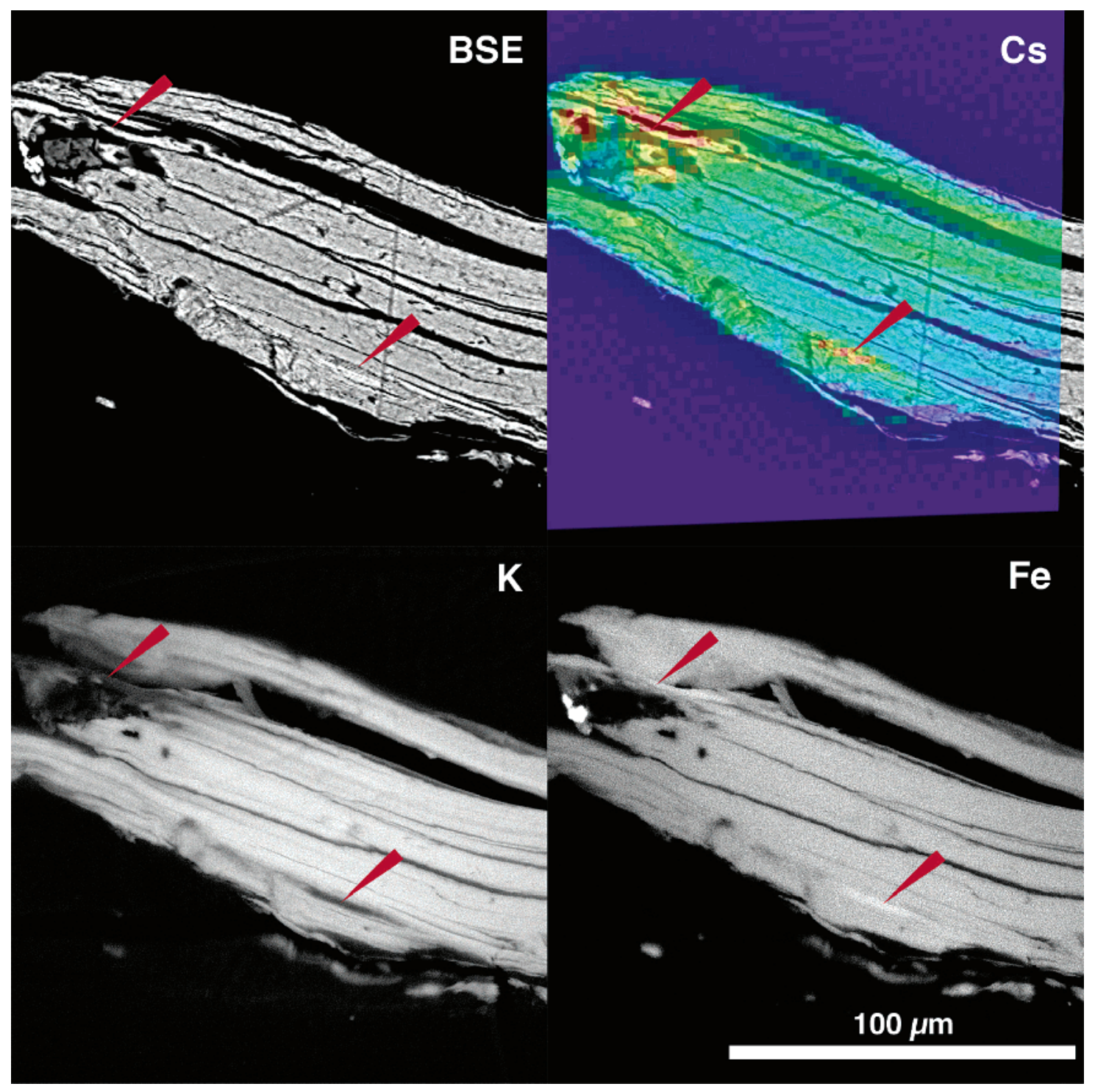

FIGURE 5. Morphology and elemental abundances for sectioned biotite clast. Arrow s indicate concentrated Cs and Fe, and depleted K.

in Hanford sediments were transported and lay as individual clasts in an aerobic environment, and were documented to exhibit alteration aureoles indicative of $\mathrm{Fe}(\mathrm{II})$ oxidation. ${ }^{11}$ More systematic studies of biotite weathering have also demonstrated theconsequences of Fe(II) oxidation. In astudy of biotite in a granitic weathering profile, ${ }^{27}$ the oxidation of octahedral-layer Fe(II) was accompanied by the pervasive loss of $\mathrm{K}^{+}$and the expulsion of divalent octahedral cations to compensate the induced charge imbalance. The combination of Fe oxidation and cation loss caused delamination and the formation of secondary minerals, and mineralstructurediscontinuities that acted as conduits for weathering solutions. This process may also have been extensive in the biotites in Hanford sediments. The localized increase in Fe abundance in Figure 5 probably resulted from the loss of $\mathrm{Fe}(\mathrm{II})$ from octahedral sites and the proximal precipitation of a ferric secondary mineral, as observed in studies where biotite was weathered experimentally. ${ }^{28} \mathrm{An} \mathrm{X}$-ray absorption near-edgestructure (XANES) analysis of areas with maximum and minimum Cs (Figure6) indicated a uniform distribution of $\mathrm{Fe}(\mathrm{III})$ throughout the clast; i.e., all structural Fe(II) was oxidized.

The evident mechanical damage from weathering and the observed compositional variations (Figure 5) suggested that Hanford biotites were pervasively altered by dissolution and the oxidation of Fe(II) to form abundant fluid-conducting

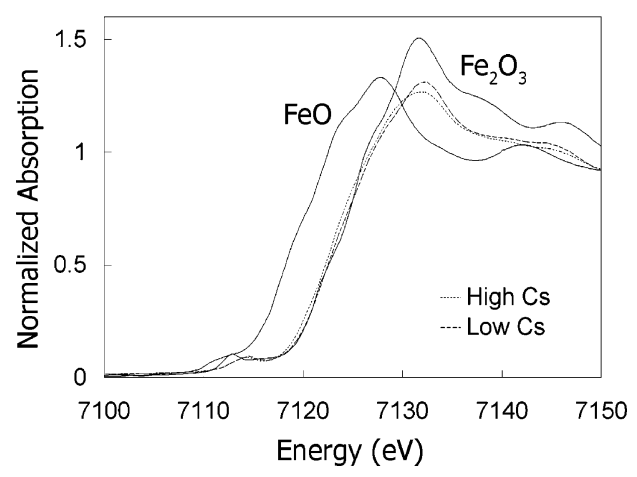

FIGURE 6. XANES spectra for high-Cs and low-Cs areas of Figure 5, compared to spectra for Fe(II) and Fe(III).

microchannels and K-depleted sites (FES) accessible by $\mathrm{Cs}^{+}$. In contrast, the Hanford muscovites contained minor Fe (not quantified; muscovites generally include up to $\left.20 \mathrm{~g} \mathrm{~kg}^{-1} \mathrm{FeO}^{7}\right)$. The development of internal zones of FES in muscovitesmay have been partially facilitated by Fe oxidation and leaching, although $\mathrm{Fe}(\mathrm{II})$ oxidation is not a prerequisitefor dissolution and FES formation. ${ }^{26}$

Cesium sorption data published in $1972^{29}$ included hypothetical mechanisms for the sorption and retention of 


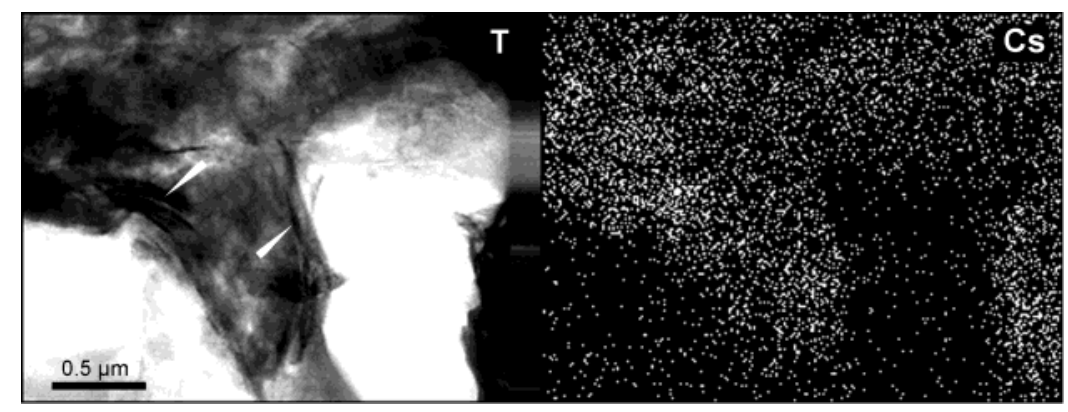

FIGURE 7. TEM image of muscovite with EELS abundance map for Cs.

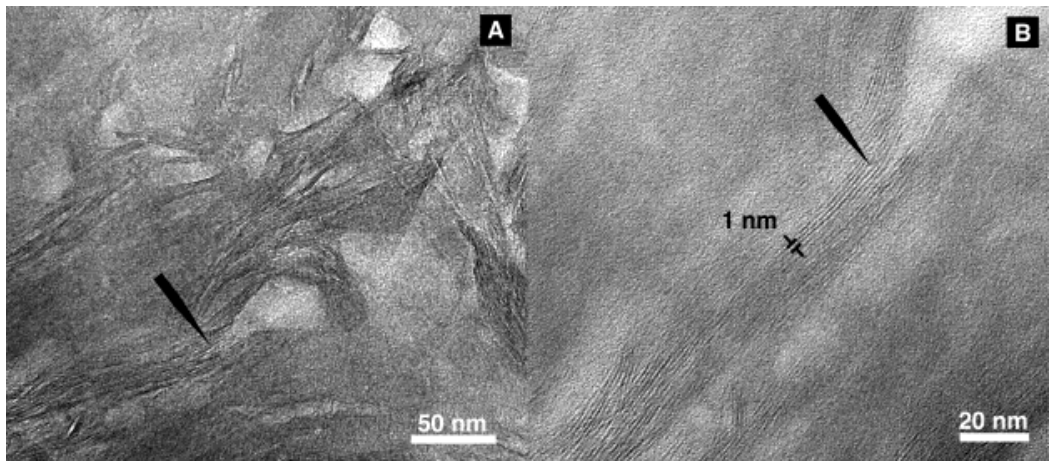

FIGURE 8. Detail of the Cs-rich area in muscovite. Lamina are parted and void spaces developed by chemical weathering (A). Parting (arrow denotes same area in parts A and B) forms wedge morphology (B).

weakly hydrated monovalent cations, includingtheir selective retention in the transition zone where $\mathrm{K}$ had been removed from interlayer space (FES), and the collapse of expanded layers after binding these ions. Our data confirm directly the sorption of $\mathrm{Cs}^{+}$to sites at theedges of micas, on a microscopic level. The mineral chemistry of trioctahedral biotites and dioctahedral muscovites suggested that muscovitecould have a greater affinity for $\mathrm{Cs}^{+}$than does biotite, as it does for $\mathrm{K}^{+}$, and experimental investigationswith thesemineralsindicated that this was so. ${ }^{30,31}$ Our data and work with ${ }^{137} \mathrm{Cs}$ contaminated sediment, 12 however, indicated that biotite retained much more $\mathrm{Cs}^{+}$in Hanford sediments than muscovite. The greater weathering of biotites in these sediments, to the extent that observable zones of $\mathrm{K}$ depletion were developed, suggested that biotite's relatively large concentration of FES could explain the higher retention of $\mathrm{CS}^{+}$.

The micrometer-scale observations of Cs concentration on mica surfaces and interiors suggested that Cs should be located in areas of observable chemical alteration on the nanometer scale. We tested this hypothesis by examining microtomed samples of muscovite using EELS to find areas of relatively abundant sorbed $\mathrm{Cs}^{+}$. Areas where Cs was abundant were found to be pervasively altered (Figure 7). Dark, intact areas of mica sheets (arrows) were bent and discontinuous, and were surrounded by areas of disrupted sheets in chaotic arrangement. On a scale where mica sheet structures weredistinguishablewithin theCs-rich area (Figure $8 \mathrm{~A})$, the muscovite showed areas where sheet structures were crenellated, and areas of arcuate subparallel sheets defining voids that could represent weathered microchannels. On the nanometer scale in the same area (Figure 8B), the $1 \mathrm{~nm}$ muscovitebasal spacing was preserved locally, butareas were also evident where sheets were parted to form FES-like structures. The residence of $\mathrm{Cs}^{+}$in micas where FES had formed was thus confirmed. These observations are consistent with the work of others who specifically investigated the effects of mica weathering, particularly the observed formation of partings and thin and curved packets of multiple sheet layers in weathered biotites. ${ }^{27}$ The existence of FES in clast interiors, and not just near clast boundaries, may help to explain $\mathrm{Cs}^{+}$desorption behavior.

The diffusive migration of $\mathrm{Cs}^{+}$into dehydrated interlayer space in micas was previously hypothesized to explain its recalcitrance to desorption, although the estimation of very slow rates for this process suggests that it is unlikely to be significant. ${ }^{4}$ Alternatively, the potential for monovalent cations to sorb to FES and cause the collapse of the mica structure $\mathrm{e}^{25,29}$ could explain slowly reversiblesorption. A recent experimental and modeling study of ${ }^{137} \mathrm{Cs}^{+}$desorption from sediments contaminated 30 years ago invoked this process. ${ }^{8}$

The broad distribution, shown here, of Cs within biotites, and the development of concentrated zones of $\mathrm{Cs}^{+} \mathrm{ac}-$ cumulation within less weathered muscovites, suggests that pore fluids can access a significant intragrain region. Weathering-induced crystal defects, cracks, and partings within the mica structure may allow the diffusive access for dissolved ions and uninterrupted water saturation through capillary forces in the unsaturated vadosezone, allowing the redistribution of $\mathrm{Cs}^{+}$from low-affinity to high-affinity sites over time. Our experiments involved short-term exposureto dissolved $\mathrm{Cs}^{+}$(up to 28 days), and this contact time was sufficient to allow significant intragrain mass transport. The $\mathrm{Cs}^{+}$was then bound by FES within the mica. The inability of many investigators to desorb significant fractions of bound $\mathrm{Cs}^{+}$could thus be explained by the sorption of $\mathrm{Cs}^{+}$to unexpectedly abundant FES within grain interiors. The slowness of desorption from these sites could beexacerbated by the partial collapse of the mica structure around $\mathrm{Cs}^{+}$ions, delaying ready exchange with desorbing cations.

\section{Acknowledgments}

This research was supported by the U.S. Department of Energy Environmental Management Science Program. The PNC-CAT is supported by funding from the Basic Energy Sciences, U.S. Department of Energy, and by the Canadian Natural Sciences and Research Council. The TEM work was performed at the W. R. Wiley Environmental Molecular Sciences Laboratory, a national scientific user facility spon- 
sored by theU .S. Department of Energy's Office of Biological and Environmental Research and located at Pacific Northwest National Laboratory (PNNL). PNNL is operated for the Department of Energy by Battelle. Wethank four anonymous reviewers whose comments were very helpful.

\section{Literature Cited}

(1) Serne, R. J.; Zachara, J. M.; Burke, D. S. Chemical Information on Tank Supernatants, Cs Adsorption From Tank Liquids Onto Hanford Sediments, and Field Observations of CsMigration From Past Tank Leaks; PNNL-11495; Pacific Northwest National Laboratory: Richland, WA, 1998.

(2) Francis, C. W.; Brinkley, F. S. Nature 1976, 260, 511-513.

(3) Evans, D. W.; Alberts, J. J.; Roy A., I. C. Geochim. Cosmochim. Acta 1983, 47, 1041-1049.

(4) Comans, R. N. J.; Haller, M.; de Preter, P. Geochim. Cosmochim. Acta 1991, 55, 433-440.

(5) Cornell, R. M. J. Radioanal. Nucl. Chem. 1993, 171, 483-500.

(6) Poinssot, C.; Baeyens, B.; Bradbury, M. H. Geochim. Cosmochim. Acta 1999, 63, 3217-3227.

(7) Deer, W. A.; Howie, R. A.; Zussman, J. Rock-Forming Minerals, Volume 3. Sheet Silicates; Longmans: London, 1976

(8) Liu, C.; Zachara, J. M.; Smith, S. C.; McKinley, J. P.; Ainsworth, C. C. Geochim. Cosmochim. Acta 2003, 67, 2893-2912.

(9) Liu, C.; Zachara, J. M.; Qafoku, O.; Smith, S. C. Environ. Sci. Technol. 2003, 37, 2640-2645.

(10) Liu, C.; Zachara, J. M.; Smith, S. C. J. Contam. Hydrol., in press.

(11) Zachara, J. M.; Smith, S. C.; Liu, C.; M cKinley, J. P.; Serne, R. J.; Gassman, P. L. Geochim. Cosmochim. Acta 2002, 66, 193-211.

(12) McKinley, J. P.; Zeissler, C. J.; Zachara, J. M.; Serne, R. J.; Lindstrom, R. M.; Schaef, H. T.; Orr, R. D. Environ. Sci. Technol. 2001, 35, 3433-3441.

(13) Comans, R. N. J.; Hockley, D. E. Geochim. Cosmochim. Acta 1992, 56, 1157-1164.

(14) Sawhney, B. L. Clays Clay Miner. 1970, 18, 47-52.
(15) Grutter, A.; Gunten, H. R. v.; Kohler, M.; Rossler, E. Radiochim. Acta 1990, 50, 177-184.

(16) Rajec, P.; Sucha, V.; Eberl, D. D.; Srodon, J.; Elsass, F. Clays Clay Miner. 1999, 47, 755-760.

(17) De Preter, P.; Van Loon, L.; Maes, A.; Cremers, A. Radiochim. Acta 1991, 52/53, 299-302.

(18) Brouwer, E.; Baeyens, B.; Cremers, A. J. Phys. Chem. 1983, 87, $1213-1219$.

(19) Liu, D.-C.; Hsu, C.-N.; Chuang, C.-L. Appl. Radiat. Isot. 1995, $46,839-846$.

(20) Klobe, W. D.; Gast, R. G. Soil. Sci. Soc. Am. Proc. 1970, 34, 746750.

(21) Liu, C.; Zachara, J. M.; Qafoku, O.; Smith, S. C. Submitted for publication.

(22) Smith, J. T.; Comans, R. N. J. Geochim. Cosmochim. Acta 1996, 60, 995-1004

(23) Heald, S. M.; Brewe, D. L.; Stern, E. A.; Kim, K. H.; Brown, F. C.; Jiang, D. T.; Crozier, E. D.; Gordon, R. A. J. Synth. Radiat. 1999, $6,347-349$.

(24) Jackson, M. L.; Sherman, G. D. Adv. Agron. 1953, 5, 219-318.

(25) Le Roux, J.; Rich, C. I.; Ribbe, P. H. Clays Clay Miner. 1970, 18, 333-338.

(26) Banfield, J. F.; Eggleton, R. A. Clays Clay Miner. 1988, 36, 47-60.

(27) Jeong, G. Y.; Kim, H. B. Am. Mineral. 2003, 88, 352-364.

(28) Murakami, T.; Utsinomiya, S.; Yokoyama, T.; Kasama, T. Am Mineral. 2003, 88, 377-386.

(29) Sawhney, B. L. Clays Clay Miner. 1972, 20, 93-100.

(30) Dolcater, D. L.; Lotse, E. G.; Syers, J. K.; Jackson, M. L. Soil. Sci. Soc. Am. Proc. 1968, 32, 795-798.

(31) Torstenfelt, B.; Andersson, K.; Allard, B. Chem. Geol. 1982, 36 123-137.

Received for review June 6, 2003. Revised manuscript received October 30, 2003. Accepted November 14, 2003.

ES034569M 